\title{
Robot Assisted Nephron Sparing Surgery in a L-Shaped Fused Ectopic Pelvic Kidney: Reproducibility of the Procedure and Technical Considerations
}

\author{
Santosh Kumar*, Aditya Prakash Sharma, Manjeet Kumar and Tushar Aditya Narain \\ Department of Urology, Advanced Urology Center, Postgraduate Institute of Medical Education and Research, Chandigarh, India
}

Keywords: Kidney; L-shaped ectopic pelvic kidney; Tumor; Robotassisted heminephrectomy

\section{Introduction}

Crossed fused ectopia of the kidneys is a rare anomaly and tumours arising in them are rarer still. We report a case of a renal cell carcinoma arising in an L shaped crossed fused ectopic kidney in a 38 year old man for whom a robot assisted nephron sparing surgery was done. Our report highlights the importance of preoperative contrast enhanced computerized tomography (CECT) with arterial 3D reconstruction for preoperative surgical planning and the use of daVinci robot (Intuitive Surgical Inc., Sunnyvale, CA, USA) in performing the heminephrectomy with utmost precision. We have earlier reported the use of the robot for heminephrectomy in a patient with chromophobe renal cell carcinoma in a crossed fused ectopic kidney and this report highlights the technical aspects of the surgical procedure and establishes the reproducibility of the same.

\section{Case Report}

A 38-year old man presented with left flank pain since 3 months on examination found to have well defined retroperitoneal lump palpable in umbilical and left lumbar region extending to left iliac fossa. Ultrasound was suggestive of Left renal mass in L shaped fused ectopic kidney.

A dedicated multiphasic CECT abdomen and pelvis with 3D reconstruction was requested (Figure 1). It was suggestive of enhancing heterogenous hypervascular mass of $8.4 \times 6.5 \times 9.1 \mathrm{~cm}$ located on lower border of L3 to S2 vertebra. Right renal moiety was lying in presacral

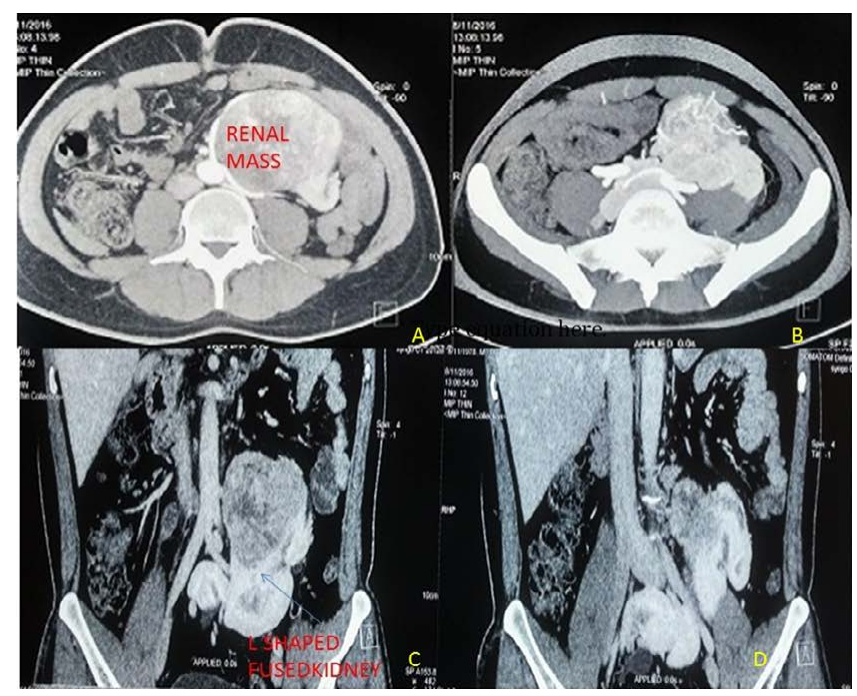

Figure 1: A dedicated multiphasic CECT Abdomen and pelvis with 3D reconstruction was requested. region and left renal moiety bearing mass lying in lumbar region. Two renal arteries were seen arising from aorta at L4 level. Another aberrant artery arising from right common iliac artery was seen (Figures 2 and 3). Right and left renal veins were seen joining the vena cava just above the bifurcation. Left pelvicalyceal system was bifid, not dilated, with left ureter was seen draining normally into urinary bladder. Right pelvicalyceal system was facing anteriorly and ureter was seen crossing to other side and entering into urinary bladder.

Patient was planned for Robot assisted left heminephrectomy. After the preanesthetic check-up; the patient underwent robot-assisted radical heminephrectomy on the left side under general anaesthesia. Right ureteric catheterization was done. The patient was placed in the right lateral position and was well secured with adequate pressure padding. Pneumoperitoneum was created by using a Verees needle through an umbilical incision. A $12 \mathrm{~mm}$ trocar was inserted cranial to the umbilicus and a 30-degree scope was introduced. Two $8 \mathrm{~mm}$

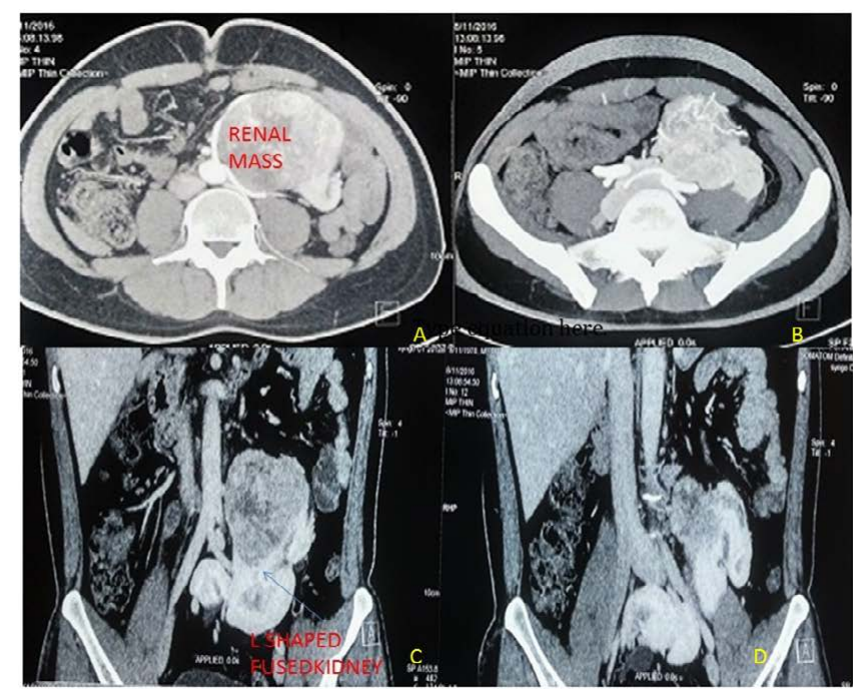

Figure 2: Two renal arteries were seen arising from aorta at L4 level

*Corresponding author: Santosh Kumar, Department of Urology, Advanced Urology Center, Postgraduate Institute of Medical Education and Research. Chandigarh, India, Tel: +919417374067; E-mail: santoshsp1967jaimatadi@yahoo.co.in

Received July 17, 2017; Accepted August 14, 2017; Published August 21, 2017 Citation: Kumar S, Sharma AP, Kumar M, Narain TA (2017) Robot Assisted Nephron Sparing Surgery in a L-Shaped Fused Ectopic Pelvic Kidney: Reproducibility of the Procedure and Technical Considerations. Adv Robot Autom 6: 171. doi: 10.4172/2168-9695.1000171

Copyright: $\odot 2017$ Kumar S, et al. This is an open-access article distributed under the terms of the Creative Commons Attribution License, which permits unrestricted use, distribution, and reproduction in any medium, provided the original author and source are credited. 
Citation: Kumar S, Sharma AP, Kumar M, Narain TA (2017) Robot Assisted Nephron Sparing Surgery in a L-Shaped Fused Ectopic Pelvic Kidney: Reproducibility of the Procedure and Technical Considerations. Adv Robot Autom 6: 171. doi: 10.4172/2168-9695.1000171

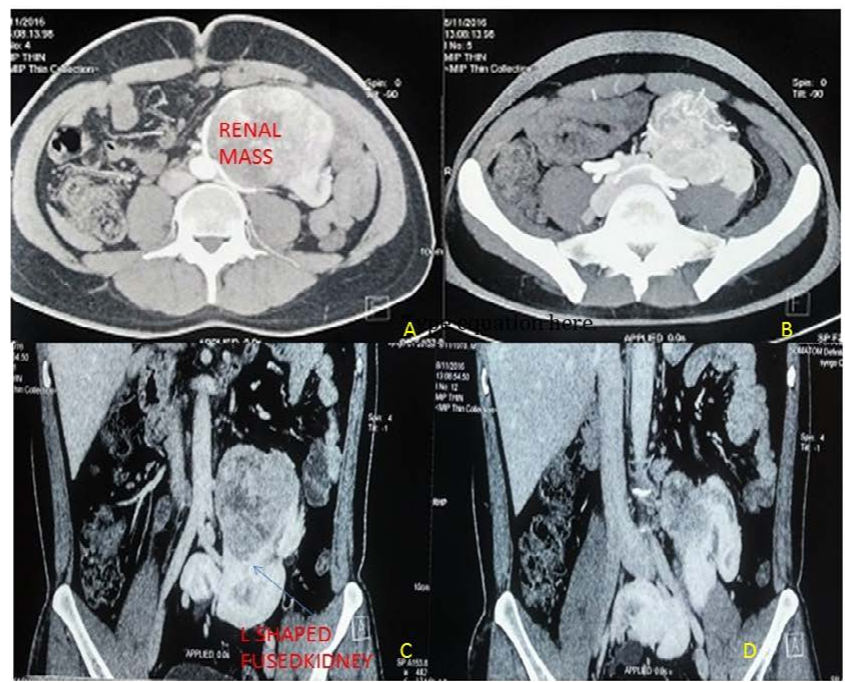

Figure 3: Right and left renal veins were seen joining the vena cava just above the bifurcation.

robotic working ports were placed in modified positions one in midclavicular line infracostally and second robotic port was inserted in the line of umbilicus about two fingers above the pubic symphysis. Another $12 \mathrm{~mm}$ assistant port was placed between the camera and caudal port. Docking of the robot was also done in a slight modified side docking fashion. The tumour was visualized through the mesentery. Transmesentric dissection of mass was done (Figure 4). On the basis of the preoperative cross-sectional imaging, arteries supplying the tumor were identified and clipped with hem-o-lok. The lower limit of the tumor was meticulously dissected off from the ectopic moiety with preservation of its vasculature. Identification, clipping, and division of this vascular pedicle achieved hemostasis. Mesocolic vessels were preserved. Peripheral feeders to renal mass were clipped and divided. Plane of cleavage was found between both moieties (Figure 5). Mesocolon was closed with vicryl 2-0. Specimen was retrieved through assistant port through indigenous bag. An 18 french drain was placed and the port closure was done using vicryl 2-0. The mean operative time was $90 \mathrm{~min}$ and the blood loss was $100 \mathrm{~mL}$.

Postoperative course was essentially uneventful. Per urethral catheter removed on postoperative day 1 . The drain output was minimal and was removed on second postoperative day. Histopathology revealed of clear cell carcinoma with Fuhrman grade II with all margins free of tumor.

\section{Discussion}

First reported case of crossed ectopia was described by Pamarolus in 1654. Crossed fused ectopia is reported in 1 in 1000 live birth second only to horse shoe kidneys [1]. Males are more commonly affected by this congenital disorder [1]. The right to left crossed fusion is more common than left to right fusion anomaly $[1,2]$. The ureteric bud enters the metanephric blastema adjacent to the anlage of the lumbosacral spine. During the next 4 weeks, the developing kidney comes to lie at the level of the L1-L3 vertebrae [3]. Fusion of the metanephric masses may occur when the renal anlagen are still in the true pelvis before or at the start of cephalad migration, or it may occur during the latter stages of ascent. A number of theories regarding crossover have been described which include : pressure from abnormally placed umbilical arteries that prevent cephalad migration of the renal unit, wandering

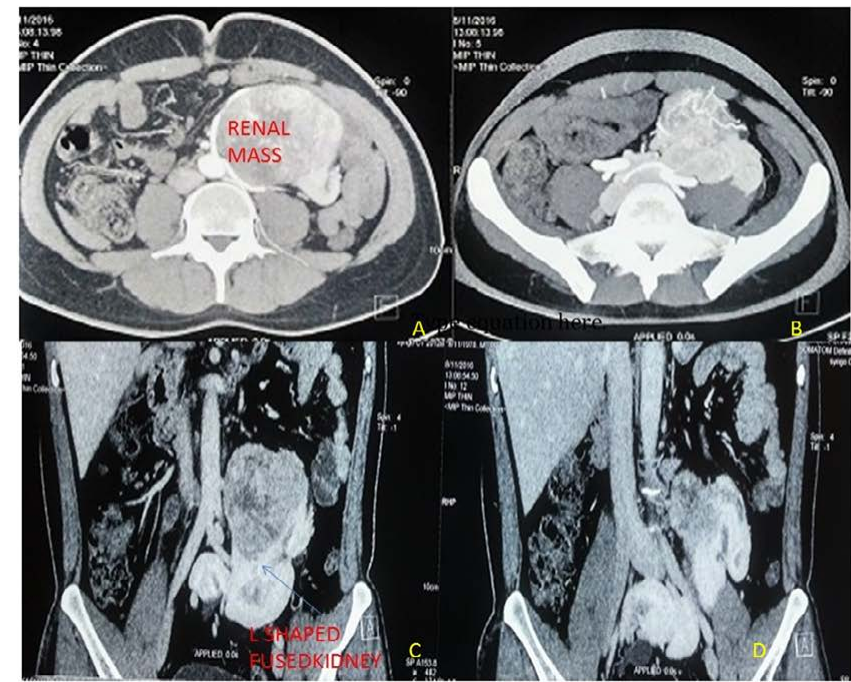

Figure 4: Docking of the robot was also done in a slight modified side docking fashion.

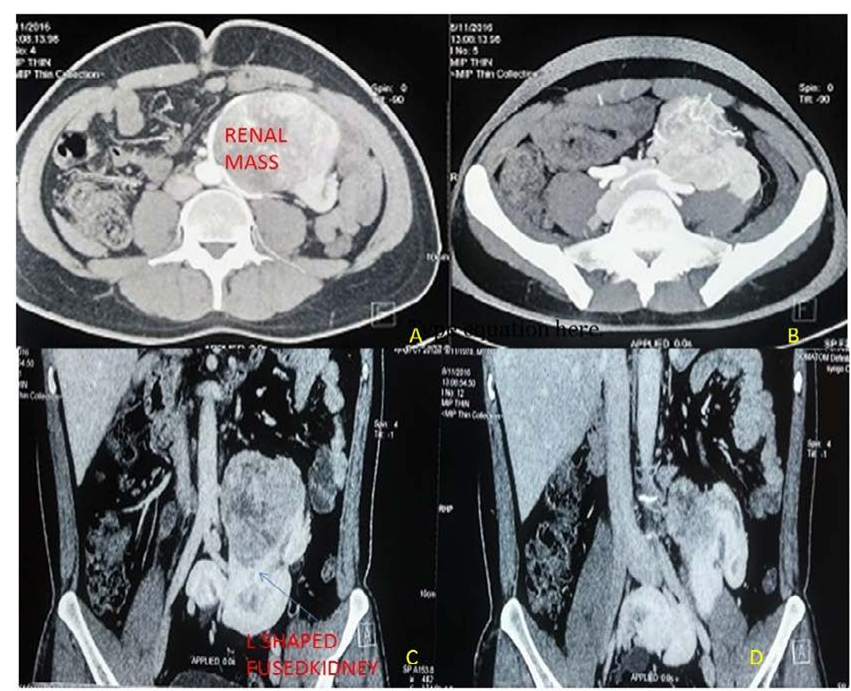

Figure 5: Plane of cleavage was found between both moieties.

of ureteric bud to the opposite side and inducing differentiation of the contralateral nephrogenic anlage or malalignment and abnormal rotation of the caudal end of the developing foetus.

The ectopic moiety may be affected by ectopic ureteral orifice, cystic dysplasia, vision-ureteric reflux, infection, stone disease, volvulus or obstruction [1]. However, the risk of malignancy does not appear to be higher than that in general population [1]. Only eight such cases of crossed fused ectopia with malignancy have been reported [4,5]. We have earlier performed a similar surgery robotically [6]. This case report reflects the reproducibility of the procedure and strengthens evidence for the same.

The surgical challenges in such cases are abnormal anatomy with aberrant vessels. To obtain a complete oncological clearance while at the same time preventing injury to colonic vessels and to the vessels supplying the normal moiety is a major concern. Another important consideration is to dissect the normal moiety from the 
Citation: Kumar S, Sharma AP, Kumar M, Narain TA (2017) Robot Assisted Nephron Sparing Surgery in a L-Shaped Fused Ectopic Pelvic Kidney: Reproducibility of the Procedure and Technical Considerations. Adv Robot Autom 6: 171. doi: 10.4172/2168-9695.1000171

Page 3 of 3

abnormal moiety. A CECT with 3D reconstruction should be done for preoperative planning.

Regardless of the type of ectopia and fusion, the vascular supply of both the orthotopic and the ectopic moiety is highly variable and unpredictable [7-12]. One or more renal arteries arising at a variable level from the aorta or common iliac vessels may supply the renal units. As noted in our case, preoperative CECT with 3D reconstructed imaging helps in surgical planning in such cases. It clearly depicts the aberrant vessels and the vessels supplying the normal moiety [12-14]. It also helps in planning the placement of ports which is one of the most crucial steps in performing a robotic resection.

We modified both the port placement and docking to our advantage for better dissection in the lower quadrant. These subtle modifications help in better ergonomics in dealing with the pathology. The 3D vision and magnification help in easier identification of the aberrant vessels thereby minimizing blood loss from inadvertent injury. The seven degrees of freedom to the endowrist instruments helps in meticulous dissection in such difficult cases. Again following the surgical principle followed in earlier case we kept the dissection close to the tumor mass. Robotic assistance resulted in a shorter incision length and earlier convalescence and return to work.

Robot assisted approach for such complex cases provides all the advantages of open surgery and at the same time comes with all the benefits of a minimally invasive procedure.

\section{References}

1. Bauer SB (2002) Anomalies of the upper urinary tract. In: Walsh PC, Retik $A B$, Vaughan DE, Wein AJ, editors. Campbell's urology. Philadelphia, PA: WB Saunders, p: 1900

2. Abeshouse BS, Bhisitkul (1959) In: Crossed renal ectopia with and without fusion. Urollnt 9: 61-63.
3. Solanki S, Bhatnagar V, Gupta AK (2013) Crossed fused renal ectopia: challenges in diagnosis and management. J Indian Assoc Pediatr Surg 18: 1-7.

4. Romero FR, Chan DY, MuntenerM, Bagga HS, Brito FA, Kavoussi LR (2007) Laparoscopic heminephrectomy for renal cell carcinoma in cross-fused ectopic kidney. Urology 69: 3-11.

5. Stimac G, Dimanovski J, RuzicB, Spajic B, Kraus O (2004) Tumors in kidney fusion anomalies--report of five cases and review of the literature. Scand J Urol Nephrol 38: 485-489.

6. Kumar S, Singh S, Jain S, Bora GS, Singh SK (2015) Robot-assisted heminephrectomy for chromophobe renal cell carcinoma in L-shaped fused crossed ectopia: Surgical challenge. Korean Journal of Urology 56: 729-732.

7. Glodny B, Petersen J, Hofmann KJ (2009) Kidney fusion anomalies revisited: clinical and radiological analysis of 209 cases of crossed fused ectopia and horseshoe kidney. BJU Int 103: 221-224.

8. Turkvatan A, Olcer T and Cumhur T (2009) Multidetector CT urography of renal fusion anomalies. DiagnInterv Radiol 15: 127-134.

9. Nowroozi MR, Ghorbani H, Amini E, Arbab A, Ghadian A (2015) Unusual presentation of renal cell carcinoma in crossed ectopic kidney. Nephro-urology monthly 7: e26760

10. Cakmak O, Isoglu CS, Peker EA, Tarhan H, Kucuk U, et al., (2016) Rena cell carcinoma in patient with crossed fused renal ectopia. Archivio Italiano di Urologia e Andrologia 87:330-331.

11. Gur U, Yossepowitch O, Baniel J (2003) Transitional cell carcinoma in a fused crossed ectopic kidney. Urology 62: 742-748.

12. Kraus O (2004) A Rare Case of Renal Cell Carcinoma in a Patient with Crossed-Fused Ectopia: Surgical and Radiologic Considerations. Acta Clin Croat 43: 302-305.

13. Tsunoe H, Yasumasu T, Tanaka M, Kai N, Naito S (2001) Resection of an Lshaped kidney with renal cell carcinoma using a microwave tissue coagulator International Journal of Urology 8: 459-462.

14. Sugita S, Kawashima H, Nakatani T, Yoshimura R, Wada S (2000) Renal cel carcinoma in an L-shaped kidney. International Journal of Urology 7: 236-238. 